\title{
Microstructure and phase composition of Fe-based self-fluxing alloy coatings formed by laser remelting and superficially modified by laser alloying with $\mathrm{B}_{4} \mathrm{C}$ particulates
}

\author{
E. E. Feldshtein ${ }^{1 *}$, M. A. Kardapolava ${ }^{2}$, O. V. Dyachenko ${ }^{3}$ \\ ${ }^{1}$ Faculty of Mechanical Engineering, University of Zielona Góra, Prof. Z. Szafrana 4, 65-516 Zielona Góra, Poland \\ ${ }^{2}$ Faculty of Mechanical Engineering, Belarusian National Technical University, \\ Khmelnitsky str. 9, Build. 6, 220013 Minsk, Belarus \\ ${ }^{3}$ Marketing, Management and Entrepreneurship Faculty, Belarusian National Technical University, \\ Nezavisimosty Ave 65, Build. 18a, 220013 Minsk, Belarus
}

Received 17 May 2014, received in revised form 9 October 2014, accepted 9 October 2014

\begin{abstract}
In the present paper, the influence of laser remelting and superficial laser alloying conditions on the structure and phases of Fe-based self-fluxing alloy coatings is studied. The laser spot speed influences the changes of alloy structures and composition considerably. The presence of alloyed $\alpha$-Fe and $\gamma$-Fe and a lot of hard inclusions, such as $\mathrm{FeB}$ and $\mathrm{CrB}, \mathrm{Fe}_{3} \mathrm{C}, \mathrm{VC}$, $\mathrm{Cr}_{3} \mathrm{C}_{2}$ and $\mathrm{B}_{4} \mathrm{C}$, was revealed. Laser alloying with add-in reinforced $\mathrm{B}_{4} \mathrm{C}$ particulates affects the structure and phases composition of the coating significantly.
\end{abstract}

Ke y words: Fe-based self-fluxing alloy, laser remelting, laser alloying, structure, phase composition, microhardness

\section{Introduction}

The surface condition of machine parts affects many of their properties. An optimum combination of properties of the part material usually represents a compromise between the required surface operational characteristics (wear resistance, corrosion resistance, etc.) and the necessary bulk material properties (strength, toughness, etc.). Parts with optimal properties can be produced by improving their surface processing technology, including coating.

From among the various coating technologies, plasma spraying methods have been extensively developed [1]. To form surface layers with good operational properties, laser methods have been extensively developed in recent years. Particularly, they allow the strengthening of the surface by hardening or additional alloying $[2,3]$. Coating technologies may be applied both when producing new parts and when repairing worn parts [4]. In the latter case, parts from steels [5, 6], irons [7, 8], titanium alloys [9], superalloys [10], etc. may be treated.
Three groups of materials have a substantial share in the materials used for plasma and laser treatment: Fe-based, Ni-based, and Co-based self-fluxing alloys [11-13]. The Ni- and Co-based self-fluxing alloys have very good overall properties but their main disadvantage is the high cost. If the properties of Fe-based alloys were enhanced, the Ni-based self fluxing alloys would be replaced by Fe-based alloys which have a high wear resistance and are relatively cheap [11, 14, 15].

Iron, carbon, manganese, silicon, boron, and other alloying elements are used as the main elements of the powder mixture to create good operational properties of eutectic Fe-based coatings. These elements form the eutectic and other high-strength components (carbides, borides, complex alloyed phases) which interact among themselves at the temperature of forming of the eutectic. Such components also provide a high hardness and wear resistance as well as a relatively high ductility of the coating. Because of such alloying, a highly dispersed quasi-eutectic structure is formed in the crystallization. Such specificity largely predetermines

\footnotetext{
*Corresponding author: tel.: +48 68 3282504; fax: +4868 3282497; e-mail address: E.Feldsztein@ibem.uz.zgora.pl
} 
Table 1. Chemical composition of the initial powder

\begin{tabular}{ccccccccc}
\hline \multicolumn{10}{c}{ Elements (wt.\%) } \\
\hline $\mathrm{Fe}$ & $\mathrm{B}$ & $\mathrm{Cr}$ & $\mathrm{Si}$ & $\mathrm{Mn}$ & $\mathrm{C}$ & $\mathrm{V}$ & $\mathrm{Al}$ & $\mathrm{Cu}$ \\
\hline Base & $3.3-4.3$ & $3.5-4.5$ & $2.0-2.5$ & $2.0-2.5$ & $1.0-1.2$ & $0.5-0.9$ & $0.05-0.5$ & $0.05-0.5$ \\
\hline
\end{tabular}

Fe-based coatings advantages over other materials.

The information about the properties of Fe-based self-fluxing alloys is limited. It was found that the $\mathrm{FeCrBSi} / \mathrm{FeS}$ composite layer exhibited frictionreducing effects and an obvious wear resistance in different lubricant conditions in comparison with 1045 steel. Fe-based self-fluxing alloys have a good corrosion resistance and make it possible to obtain a multiphase structure combining a finely dispersed eutectic with a low hardness and an iron borocarbide hard phase, which is the optimum for rubbing pairs operating with high loads and sliding speeds [14].

One of the trends to improve operational properties of surface layers is additional laser alloying with reinforcing particulates. Different materials may be used for this purpose: boron carbides [16-18] and pure boron [19], tungsten carbides [20], Fe-Al powder [21], zirconium oxides [22]. Such additives form manycomponent structures that affect the microhardness, stresses, wear and corrosion resistance. Particularly, the thermal expansion coefficients of $\mathrm{B}_{4} \mathrm{C}$ particles and the Fe-based substrate are different. This leads to the formation of compressive residual stresses in coatings that enhance their wear resistance. In addition, $\mathrm{B}_{4} \mathrm{C}$ particulates, due to their high melting temperature, remain in solid phase in the molten coating.

The aim of this work is to analyze the structure, phase composition and microhardness of the Fe-based self-fluxing alloy after laser remelting and add-in surface alloying with $\mathrm{B}_{4} \mathrm{C}$ particulates depending on the laser spot speed.

\section{Materials and methods}

The Cr4Mn2B4Si2V1 powder of the Fe-Cr-B-Si system was used for coating (Table 1). The AISI 1045 steel was used as the substrate material. The samples were subjected to bead blasting before plasma spraying.

A UPU-3D plasma spray unit was used for preliminary coating with a plasma gun. This unit allows the deposition of a wide range of various powder materials: carbides, silicides, oxides, self-fluxing alloys, etc. Nitrogen under pressure of $0.6 \mathrm{MPa}$ was used as the plasma-forming gas. Spraying was carried out in the following conditions: the current of $250 \mathrm{~A}$ and the voltage of $80 \mathrm{~V}$. The coating thickness of
$0.7 \pm 0.05 \mathrm{~mm}$ was provided using the magnetic thickness tool MT-40 NC.

After deposition, the samples were remelted with a laser beam. The LGN-702 $\mathrm{CO}_{2}$ continuous wave laser operating at $800 \mathrm{~W}$ output power was used for laser remelting and alloying. Scan speeds of $0.83,1.67,2.5$, 3.33 and $5 \mathrm{~mm} \mathrm{~s}^{-1}$ were used and nitrogen acted as the drag gas. A laser spot diameter of $1.0 \mathrm{~mm}$ was used, which corresponds to a power density of about $1 \times$ $10^{5} \mathrm{~W} \mathrm{~cm}^{-2}$. In order to obtain a uniform phase composition and the desired properties across the coating thickness, an overlap ratio between tracks of 0.8 was used.

When laser alloying, add-in mixture of 75 vol.\% $\mathrm{B}_{4} \mathrm{C}$ particulates with 3 vol.\% of a nitrocellulose glue and water was hand-brushed on the samples. A thickness of $0.1 \pm 0.05 \mathrm{~mm}$ was generated. The magnetic thickness tool MR-40 NC was used for measurement.

The structures of the coatings were studied using a metallographic microscope and SEM. The microhardness was measured with a load of $\sim 50 \mathrm{~N}$.

An X-ray diffraction method was used to identify the phases in remelted/alloyed zones. Investigations were carried out using a DRON 3.0 computer-controlled diffractometer at a sample rotation speed of $1 \mathrm{deg} \mathrm{min}^{-1}$ in $\mathrm{Cu} \alpha$ monochromatic radiation with an angular range from $10^{\circ}$ to $78^{\circ}$.

\section{Results and discussion}

The study of structures of coatings alloyed with $\mathrm{B}_{4} \mathrm{C}$ and remelted by the laser beam showed that they vary with the increase of the spot speed. At a speed of $0.83 \mathrm{~mm} \mathrm{~s}^{-1}$ a cast equilibrium cellular structure with splashes of dendrites is formed (Fig. 1a). This is an evidence of a rather long stay of the coating in the laser irradiation zone that led to the redistribution of elements in the coating. When the spot speed is increased, the time of the remelting action is reduced. When the speed increases up to $1.67 \mathrm{~mm} \mathrm{~s}^{-1}$, dendrites appear in the structure, with first-order axes oriented at $45^{\circ}$ to the direction of the heat sink. A further speed growth up to $3.33 \mathrm{~mm} \mathrm{~s}^{-1}$ led to the formation of a supersaturated solid solution, from which fine borides and carbides of irregular shapes were precipitated. Increasing the spot speed to $5 \mathrm{~mm} \mathrm{~s}^{-1}$ reduces the time of coating melting, whereby a fine supersaturated solid solution is formed from the primary solid 

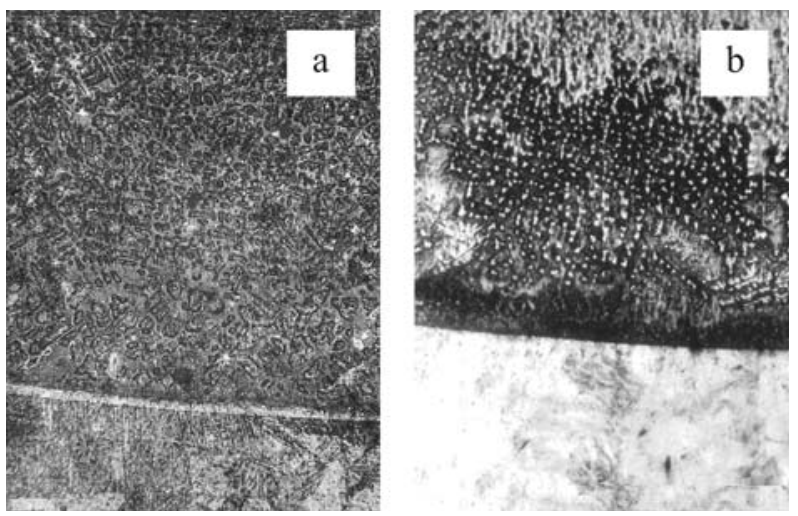

Fig. 1. Coating microstructures after laser alloying with $\mathrm{B}_{4} \mathrm{C}$ particulates with different spot speeds: a) 0.83 $\mathrm{mm} \mathrm{s}^{-1}$, b) $5 \mathrm{~mm} \mathrm{~s}^{-1}(\times 400)$.

solution, and when the coating is cooled small borides and carbides in the form of quasi-eutectic drop out (Fig. 1b). A darker transition zone indicates insufficient melting between the coating and the substrate material.

The content of alloying elements was analyzed quantitatively by using SEM analysis. When the spot speed is equal to $0.83 \mathrm{~mm} \mathrm{~s}^{-1}$, small dendrites are the predominant structure, whose axes are oriented in the direction of the heat sink (Fig. 2a). At higher speeds, the structure is a supersaturated solid solution with precipitates of carbides and borides of sizes up to 5.8 microns (Fig. 2b).

In order to determine the changes in the chemical composition of coatings depending on the spot speed, the SEM analysis was conducted over the dendrites body and in the area between them (Table 2). It was found that the dendrites are enriched with chromium. The dendrites with the axes of the first order crystallize in the first place and are ultimately enriched in chromium: $3.18-3.98 \%$. The microhardness of the dendrites was HV50 $=950-1010$. The areas around the dendrite axes of the second order are less enriched with alloying elements, in particular, chromium (3.28\%). Contents of chromium and vanadium in the area between the dendrites confirm the formation of mixture phases, including borides and carbides of chromium and vanadium. Reducing the content of alloying elements in the interdendritic area led to a reduction of its microhardness to HV50 $=680$. In the vicinity of the dendrites, some reduction of chromium (from 3.18$3.28 \%$ to $2.46-2.95 \%$ ) and silicon (from 1.01-1.38 \% to $0.79-1.00 \%$ ) is observed. It reduces the microhardness of the dendrites to HV50 $=840-890$. At point $\mathrm{Nr} 7$ (the dendrite area) a sharp increase in the chromium content (up to $8.15 \%$ ) and a decrease in the silicon content (up to $0.40 \%$ ) were registered. This may confirm the formation of $\mathrm{Cr}_{7} \mathrm{C}_{3}$ chromium carbide. Microhardness measurements of the base material re-
Table 2. Content of alloying elements in Fe-based coating reinforced with $\mathrm{B}_{4} \mathrm{C}$ particulates

\begin{tabular}{lccccl}
\hline \multirow{2}{*}{ Areas } & & \multicolumn{4}{c}{ Content (vol.\%) } \\
\cline { 3 - 6 } $\begin{array}{c}\text { Points } \\
\text { number }\end{array}$ & $\mathrm{Cr}$ & $\mathrm{Si}$ & $\mathrm{Mn}$ & $\mathrm{V}$ \\
\hline & 1 & 3.28 & 1.01 & 1.77 & 1.05 \\
Dendrite area & 2 & 3.18 & 1.38 & 1.97 & 0.9 \\
& 3 & 3.99 & 0.82 & 1.5 & 0.99 \\
& 4 & 3.82 & 0.57 & 1.5 & 0.91 \\
& 5 & 2.95 & 1 & 1.81 & 0.91 \\
& 6 & 2.46 & 0.79 & 1.3 & 0.45 \\
& 7 & 8.15 & 0.4 & 1.17 & 0.76 \\
& 8 & 3.81 & 0.68 & 1.39 & 0.58 \\
\hline \multirow{3}{*}{ Carbide area } & 1 & 5.18 & 0.37 & 1.56 & 1.27 \\
& 2 & 5.14 & 0.5 & 1.67 & 0.89 \\
& 3 & 3.42 & 0.57 & 1.97 & 1.12 \\
& 4 & 4.12 & 0.52 & 1.42 & 0.6 \\
& 5 & 5.71 & 0.81 & 1.35 & 0.83 \\
& 6 & 5.63 & 0.29 & 1.21 & 0.8 \\
& 7 & 4.48 & 0.46 & 1.22 & 0.57 \\
& 8 & 3.04 & 0.87 & 1.84 & 0.85 \\
& 9 & 5.02 & 0.43 & 1.05 & 0.79 \\
& 10 & 4.11 & 1.23 & 1.86 & 0.77 \\
& 11 & 5.48 & 0.82 & 1.17 & 0.83 \\
\hline
\end{tabular}

vealed its minor fluctuations $(\mathrm{HV} 50=390-430)$. In the supersaturated carbide-boride phase a significant increase, by 1.5 times, in the chromium content was registered, while the silicon content reduced about 2.52.7 times. The microhardness of this phase increases to HV50 $=1100-1545$. The chromium content in the solid solution is lower (3.04-4.12\%), and the silicon content also reduces up to $0.87-1.23 \%$. This causes a decrease in the microhardness to HV50 $=680-795$.

As it was indicated above, a self-fluxing alloy is a multicomponent system that is sensitive to heating conditions. In addition, the introduction of $\mathrm{B}_{4} \mathrm{C}$ particulates into the coating complicates the structure of the material further. The effect of laser alloying on the phase composition of these coatings is shown in Fig. 3. Compared to the unalloyed coating, the $\alpha$-Fe content is reduced by $15-20 \%$ and the $\gamma$-Fe content is reduced several times. Accordingly, the content of reinforcing phases (borides and carbides) increases, and they have a more complex composition. In particular, by analyzing the state diagrams of $\mathrm{Fe}-\mathrm{Cr}-\mathrm{Si}[23]$ and Fe-Cr-B-Si [24] Fe-based alloys it can be concluded that in the sprayed and remelted layers compounds of $(\mathrm{Cr}, \mathrm{Fe})_{23}(\mathrm{C}, \mathrm{B})_{6}$ type are formed, which are uniformly distributed in the fine-grained eutectic matrix, consisting of the solid solution of carbon, silicon and chromium in iron.

Figure 4 illustrates the effect of the spot speed on the microhardness of coatings. With increasing the speed of the laser beam, the coating microhardness 

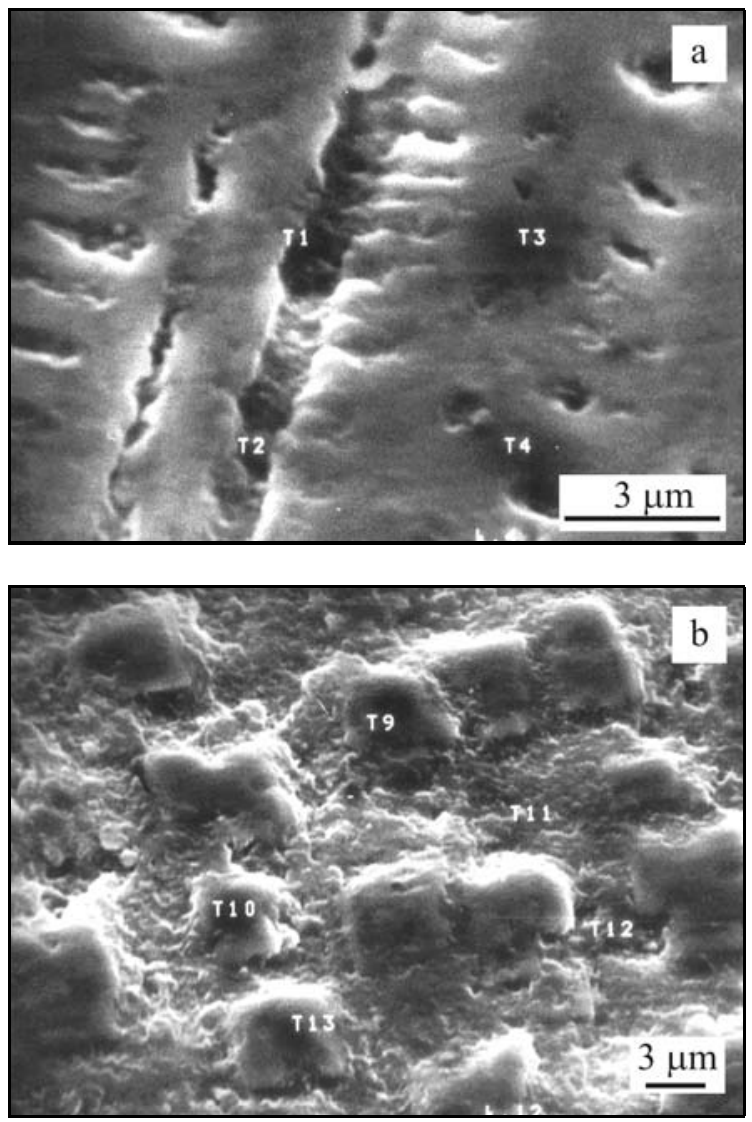

Fig. 2. SEM images of coating with $\mathrm{B}_{4} \mathrm{C}$ particulates: a) spot speed $0.83 \mathrm{~mm} \mathrm{~s}^{-1}$, b) spot speed $5 \mathrm{~mm} \mathrm{~s}^{-1}$.

increases and reaches the highest values at maximum speed. This is explained by consecutive changes of the microstructure from the equilibrium state to the supersaturated carbide-boride state (see Fig. 1). Alloying with $\mathrm{B}_{4} \mathrm{C}$ particulates increases the microhardness about 1.2 times.

\section{Conclusions}

Fe-based self-fluxing alloy coatings have been formed by plasma spraying with follow-up laser remelting using a continuous wave $\mathrm{CO}_{2}$ laser. In addition, a superficial modification of the surface by laser alloying with $\mathrm{B}_{4} \mathrm{C}$ particulates was performed.

Laser remelting leads to the formation of metastable structures, reinforced with dendrites. The fine eutectic is formed between the axes of the dendrites. $\mathrm{XRD}$ reveals the presence of alloyed $\alpha-\mathrm{Fe}$ and $\gamma-\mathrm{Fe}$ as well as a lot of hard inclusions that have been formed in the coating, such as $\mathrm{FeB}$ and $\mathrm{CrB}, \mathrm{Fe}_{3} \mathrm{C}$, $\mathrm{VC}, \mathrm{Cr}_{3} \mathrm{C}_{2}$ and $\mathrm{B}_{4} \mathrm{C}$. Technological parameters of laser remelting affect the microstructure significantly. At a laser beam speed equal to $0.83 \mathrm{~mm} \mathrm{~s}^{-1}$ an equilibrium structure of the coating was observed. Increasing the
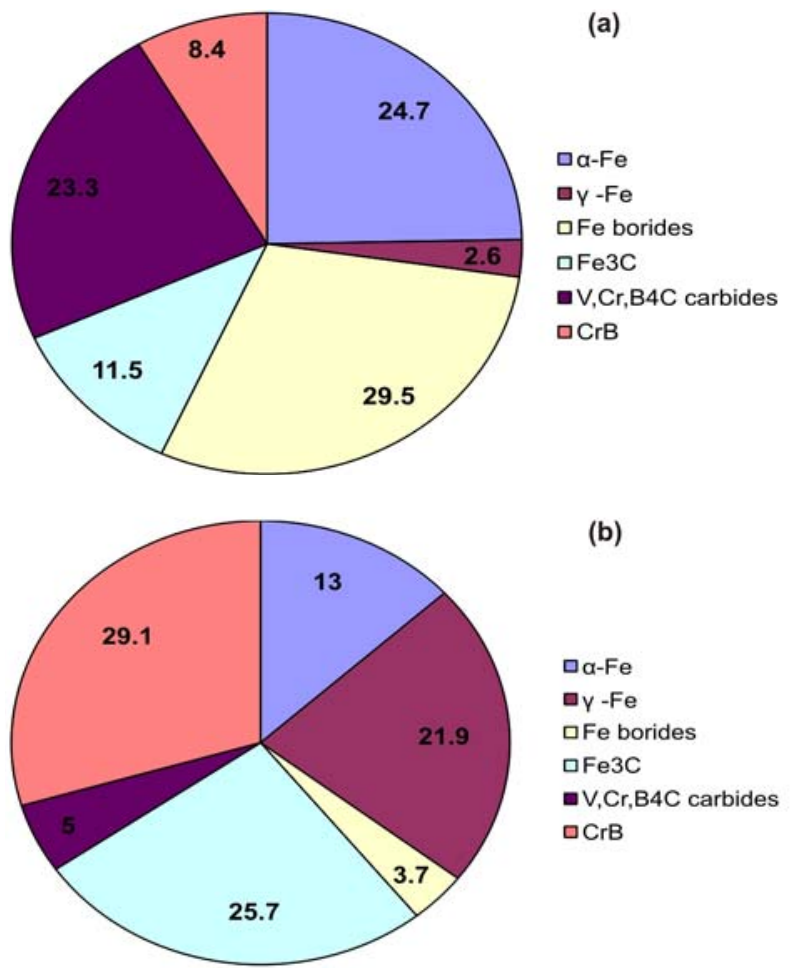

Fig. 3. Phase compositions of coating with $\mathrm{B}_{4} \mathrm{C}$ particulates: a) spot speed $0.83 \mathrm{~mm} \mathrm{~s}^{-1}, \mathrm{~b}$ ) spot speed $2.5 \mathrm{~mm} \mathrm{~s}^{-1}$.

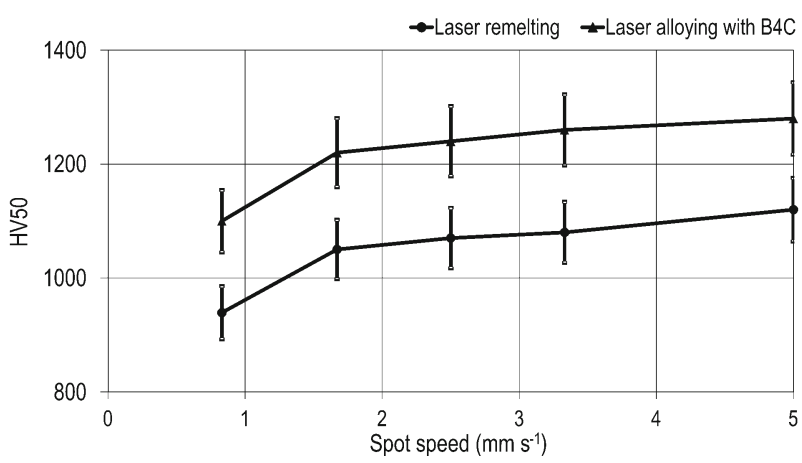

Fig. 4. The effect of the spot speed on the microhardness of coatings.

speed to $5 \mathrm{~mm} \mathrm{~s}^{-1}$ promoted the formation of a supersaturated Fe-based solid solution with inclusions of carbides and borides in the quasi-eutectic form. The microhardness of the coating increases from HV50 = 940 for $0.83 \mathrm{~mm} \mathrm{~s}^{-1}$ spot speed to HV50 $=1120$ for $5 \mathrm{~mm} \mathrm{~s}^{-1}$ spot speed.

An additional surface reinforcing with $\mathrm{B}_{4} \mathrm{C}$ particulates changes the structure of the coating significantly. At low spot speeds, it is the equilibrium structure with splashes dendrites, whereas at higher spot speeds, the structure is the fine supersaturated solid solution with small borides and carbides in the form 
of quasi-eutectics. Compared to the unalloyed coating, the $\alpha$-Fe content is reduced by $15-20 \%$ and the $\gamma$-Fe content is reduced several times. Accordingly, the content of reinforcing borides and carbides increases. As a consequence, the alloy microhardness increases about 1.2 times.

\section{References}

[1] Chattopadhyay, R.: Advanced Thermally Assisted Surface Engineering Processes. Dordrecht, Kluwer Academic Publisher 2004.

[2] Kwok, C. T. (Ed.): Laser Surface Modification of Alloys for Erosion and Corrosion Resistance. Cambridge, Woodhead Publishing Ltd. 2012. doi: $10.1533 / 9780857095831$

[3] Ion, J. C.: Laser Processing of Engineering Materials: Principles. Procedure and Industrial Application. Burlington, Elsevier Butterworth-Heinemann Linacre House 2005.

[4] Jhavar, S., Paul, C. P., Jain, N. K.: Eng. Fail. Anal., 34, 2013, p. 519. doi:10.1016/j.engfailanal.2013.09.006

[5] Tong, X., Dai, M. J., Zhang, Z. H.: Appl. Surf. Sci., 271, 2013, p. 373. doi:10.1016/j.apsusc.2013.01.209

[6] Cong, D. L., Zhou, H., Ren, Z. N., Zhang, H. F., Ren, L. Q., Meng, C., Wang, C. W.: Opt. Lasers Eng., 54, 2014, p. 55. doi:10.1016/i.optlaseng.2013.09.012

[7] Sun, G., Zhou, R., Li, P., Fenga, A., Zhang, Y.: Surf. Coat. Technol., 205, 2011, p. 2747. doi:10.1016/j.surfcoat.2010.10.032

[8] Yan, H., Wang, A., Xiong, Z. T., Xu, K. D., Huang, Z. W.: Appl. Surf. Sci., 256, 2010, p. 7001. doi:10.1016/j.apsusc.2010.05.015

[9] Wang, W., Wang, M., Jie, Z., Sun, F., Huang, D.: Opt. Lasers Eng., 46, 2008, p. 810. doi:10.1016/j.optlaseng.2008.05.015

[10] Lambarri, J., Leunda, J., García Navas, V., Soriano, C., Sanz, C.: Opt. Lasers Eng., 51, 2013, p. 813. doi:10.1016/j.optlaseng.2013.01.011
[11] Vencl, A., Mrdak, M., Cvijović, I.: FME Trans., 34, 2006, p. 151.

[12] Hemmati, I., Huizenga, R. M., Ocelík, V., De Hosson, J. Th. M.: Acta Mater., 61, 2013, p. 6061. doi:10.1016/j.actamat.2013.06.048

[13] Parthasarathi, N. L., Duraiselvam, M., Borah, U.: Mater. Des., 36, 2012, p. 141. doi:10.1016/j.matdes.2011.10.051

[14] Kang, J. J., Wang, C. B., Wang, H. D., Xu, B. S., Liu, J. J., Li, G. L.: Proc. Inst. Mech. Eng., Part J: J. Eng. Trib., 224, 2010, p. 807. doi:10.1243/13506501JET740

[15] Yao, C., Huang, J., Zhang, P., Li, Z., Wu, Y.: Appl. Surf. Sci., 257, 2011, p. 2184. doi:10.1016/j.apsusc.2010.09.070

[16] Yilbas, B. S., Patel, F., Karatas, C.: Appl. Surf. Sci., 282, 2013, p. 601. doi:10.1016/j.apsusc.2013.06.018

[17] Yilbas, B. S., Matthews, A., Leyland, A., Karatas, C., Akhtar, S. S., Aleem, B. J. A.: Appl. Surf. Sci., 263, 2012, p. 804. doi:10.1016/j.apsusc.2012.10.009

[18] Mazahery, A., Shabani, M. O.: Composites Part B: Engineering, 43, 2012, p. 1302. doi:10.1016/j.compositesb.2012.01.011

[19] Kulka, M., Dziarski, P., Makuch, N., Piasecki, A., Miklaszewski, A.: Appl. Surf. Sci., 284, 2013, p. 757. doi:10.1016/j.apsusc.2013.07.167

[20] Dobrzański, L. A., Bonek, M., Hajduczek, E., Klimpel, A.: Appl. Surf. Sci., 247, 2005, p. 328. doi:10.1016/j.apsusc.2005.01.126

[21] Abdolahi, B., Shahverdi, H. R., Torkamany, M. J., Emami, M.: Appl. Surf. Sci., 257, 2011, p. 9921. doi:10.1016/i.apsusc.2011.06.108

[22] Ng, K. W., Man, H. C., Yue, T. M.: Appl. Surf. Sci., 254, 2008, p. 6725. doi:10.1016/i.apsusc.2008.04.076

[23] Lindholm, M.: J. Phase Equilibria, 18, 1997, p. 432. doi:10.1007/BF02647699

[24] Do, J., Lee, H. J., Jeon, C., Ha, D. J., Kim, C. P., Lee, B. J., Lee, S., Shin, Y. S.: Metal. Mater. Trans. A, 43, 2012, p. 2237. doi:10.1007/s11661-012-1086-8 